\title{
A Cross Slot Coupling to Enhance Bandwidth of Dual-Layer SIW Structure
}

\author{
M. N. Hafiz, M. H. Jamaluddin*, R. Selvaraju
}

Wireless Communication Center (WCC), Universiti Teknologi Malaysia (UTM), Skudai, Johor Bharu, Malaysia

\begin{tabular}{|c|c|}
\hline Article Info & ABSTRACT \\
\hline Article history: & \multirow{8}{*}{$\begin{array}{l}\text { In this paper, design characteristics of cross slot coupling have been explored } \\
\text { and realized in a proposed dual-layer SIW prototype for bandwidth } \\
\text { enhancement at } 10.0 \mathrm{GHz} \text {. The assembled prototype consists of two SMA- } \\
\text { microstrip input/output interface with low-loss microstrip-taper via transition } \\
\text { and two manually stacked SIW structures electrically connected via a small } \\
\text { cross slot coupling design. The proposed dual-layer SIW structure is } \\
\text { designed using CST software and fabricated using conventional Printed } \\
\text { Circuit Board (PCB) manufacturing process on Rogers } 4003 \mathrm{C} \text { with } \varepsilon_{\mathrm{r}}=3.38 \\
\text { and } \mathrm{h}=0.813 \mathrm{~mm} \text {. The close agreement between simulated and measured } \\
\text { results is observed within a frequency range studied of } 9.2 \mathrm{GHz} \text { to } 11.2 \mathrm{GHz} \\
\text { with } 19.0 \% \text { bandwidth performance. The used of cross slot coupling design } \\
\text { in the assembled dual-layer SIW structure indicated } 9.0 \% \text { bandwidth } \\
\text { enhancement compared to the conventional multilayer design with } \\
\text { rectangular slot coupling. The assembled dual-layer SIW structure with cross } \\
\text { slot coupling design shows potential in several RF applications such as radar } \\
\text { and satellite communication. }\end{array}$} \\
\hline Received Nov 9, 2017 & \\
\hline Revised Jan 12, 2018 & \\
\hline Accepted Feb 23, 2018 & \\
\hline Keywords: & \\
\hline Multilayer transition design & \\
\hline Slot coupling & \\
\hline Substrate integrated waveguide & \\
\hline
\end{tabular}

Copyright $(\odot) 2018$ Institute of Advanced Engineering and Science. All rights reserved.

\section{Corresponding Author:}

Mohd Haizal Jamaluddin, Wireless Communication Center (WCC), Universiti Teknologi Malaysia (UTM), Skudai, Johor Bharu, Malaysia.

Email: haizal@utm.my

\section{INTRODUCTION (10 PT)}

Needs in RF applications at high-frequency design required designers to deliver a compact structure with low loss, light weight, and high impedance bandwidth performance as mentioned in [1-3]. Many types of multilayer transition design with slot coupling has been recently developed and investigated for low-cost design and compact structure such as [4-6]. However, the use of different types of slot coupling design in the multilayer transition design is not widely demonstrated yet as possibilities to increase the bandwidth performance.

For example, in 2009, a multilayer transition design between SIW to traditional rectangular waveguide structure is proposed by [7] in order to demonstrate a compact transition design between various types of transmission lines for millimeter wave frequency solution. The proposed transition design is realized by using a longitudinal rectangular slot coupling, which etched on the broad wall of SIW structure as an opening to couples energy from the traditional rectangular waveguide. The electrical performance of the multilayer transition design is observed within a frequency range studied with $0.8 \mathrm{GHz}$ bandwidth.

Then in 2015, a multilayer transition design between SIW to SIW structure is demonstrated by [8] as improvement of [7] in term of compactness and low-cost design solution. The multilayer transition design used two layers SIW structure as a replacement to the bulky traditional waveguide with the same type of slot coupling design but in a different orientation. The used of transverse rectangular slot coupling in the multilayer transition design shows the bandwidth of $1.0 \mathrm{GHz}$ within frequency range studied. Although the 
Multilayer transition design between two SIW layers shows improvement in term of compactness and lowcost design, however, the used of the same type slot coupling in the multilayer transition design still not promising bandwidth enhancement.

In this work, a cross slot coupling design is proposed and explored for possibilities to enhance bandwidth performance of the dual layer SIW structure. The dual-layer SIW structure with cross slot coupling is designed using CST software and realized using conventional PCB manufacturing process. The fabricated dual-layer SIW structure with cross slot coupling design is manually assembled and measured for design verification.

\section{RESEARCH METHOD}

Figure 1 shows 3D configuration design of the dual-layer SIW structure with cross slot coupling design. All the dimension involved in this design are followed SIW design rules using (1) - (3). Because SIW technology owning similarity to the rectangular waveguide, they have been obtained empirical relations between the geometrical dimensions of the SIW technology and effective width, $W$ of the rectangular waveguide. These relations allow designers to determine and design SIW components, without need of fullwave analysis tools. Therefore, the dimension of the spacing between two rows of metallic holes, $\mathrm{w}_{\mathrm{SIW}}$ in SIW technology can be determined by using (1).

$$
\mathrm{W}_{\mathrm{SIW}}=\mathrm{W}+\frac{\mathrm{d}^{2}}{0.95 \mathrm{p}}
$$

where $d$ is the diameter of metallic via hole and $p$ is the distance between two metallic via holes. Meanwhile, the values of the parameter $d$ and $p$ should be small enough to reduce leakages. These parameters can be determined using (2) and (3), respectively.

$$
\begin{aligned}
& \mathrm{d}<\frac{\lambda_{\mathrm{g}}}{5} \\
& \mathrm{p}<2 \mathrm{~d}
\end{aligned}
$$

where $\lambda g$ in (2) is guide wavelength which can be determined by using (4):

$$
\lambda_{\mathrm{g}}=\frac{2 \pi}{\sqrt{\frac{\varepsilon_{\mathrm{r}}(2 \pi \mathrm{f})^{2}}{\mathrm{c}^{2}}-\left(\frac{\pi}{\mathrm{W}}\right)^{2}}}
$$

There are three design elements in the proposed dual-layer SIW structure; microstrip-taper via transition, two basic SIW structures, and cross slot coupling. The microstrip-taper taper via transition is printed on Substrate 1 and Substrate 2 as Metallic 1 and Metallic 3, respectively for fed line of $50 \mathrm{Ohm}$ characteristics impedance matching. The two basic SIW structures are designed as Substrate 1 and Substrate 2. The cross slot coupling of unequal length is located at the common plane of the dual-layer SIW structure, which is on the Metallic 1 and Metallic 3 as an opening to allow electrical connection between SIW layers. Meanwhile, Metallic 2 and Metallic 4 acted as the ground plane. Then, Figure 1 (b) shows the configuration of the dual-layer SIW structure with cross slot coupling design after all layers are combined together as a single structure. 

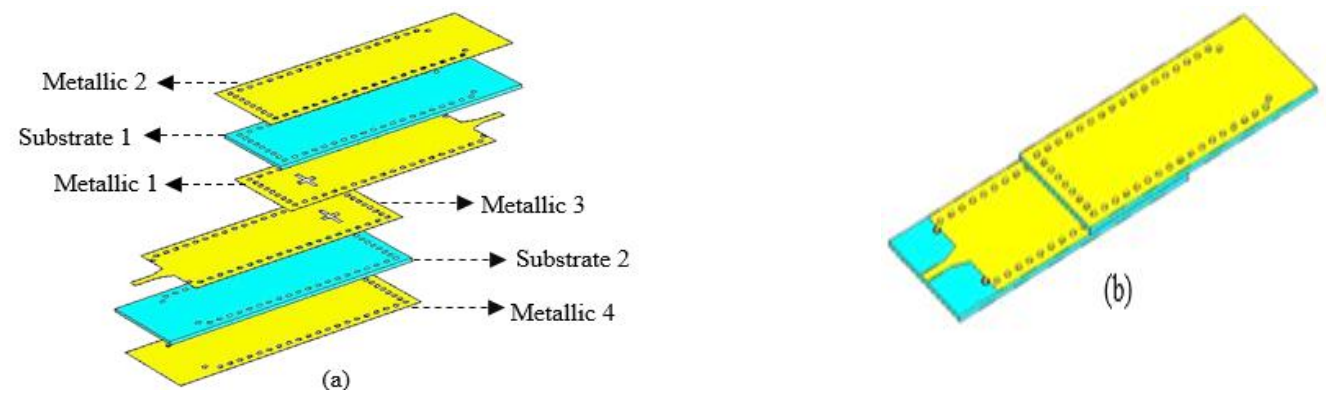

Figure 1. Configuration of Dual-layer SIW Structure with Cross Slot Coupling Design (a) Before and (b) After Stacked.

\subsection{Cross Slot Coupling Design}

Figure 2 shows the geometry of the cross-slot coupling design in the proposed dual-layer SIW structure. Basically, the cross-slot coupling design is developed by combining both transverse and longitudinal rectangular slot coupling. The idea of this combination design is based on the dominant $T E_{10}$ mode propagation signal in SIW structure as reported in [9], which contained maximum E-field at the waveguide center. Therefore, in order to allow more E-field to be coupled between SIW layers, which will increase the bandwidth performance of the structure, a size of a longitudinal rectangular slot is added at the center of the longitudinal rectangular slot as shown in Figure 2.

For the transverse rectangular slot in the cross-slot coupling design, the design parameter values are based on [8] and [10], which then optimized using CST software in order to obtain a good transition behavior in term of return loss and resonant frequencies. The optimized values are described as slot length, $\operatorname{long}_{x}=0.36 \lambda_{g}=7.0 \mathrm{~mm}$ and slot width, $\operatorname{long}_{y}=0.36 \lambda_{g}=0.7 \mathrm{~mm}$. Meanwhile, for the longitudinal slot in the cross-slot coupling design, a parametric study is performed as to characterize the size of the longitudinal slot in order to enhance the bandwidth performance. The characterized values are described as slot width, long $_{c x}=0.15 \lambda_{g}=3.0 \mathrm{~mm}$, slot length, long $_{c y}=0.06 \lambda_{g}=1.2 \mathrm{~mm}$, and slot distance, dist $t_{c x}=0.42 \lambda_{g}=8.0$ $\mathrm{mm}$.

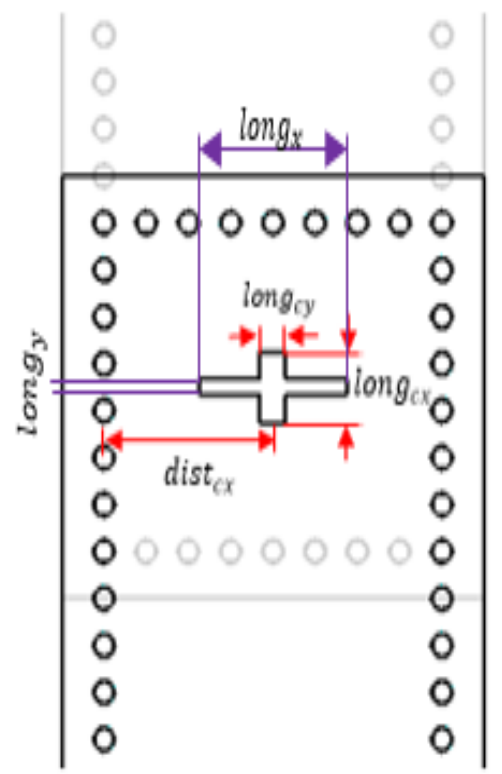

Figure 2. The Geometry of Cross Slot Coupling Design in the Dual-layer SIW Structure.

\section{RESULTS AND ANALYSIS}

The fabricated dual-layer SIW structure with cross slot coupling design is shown in Figure 3. The proposed dual-layer SIW structure is manually assembled by stacking each layer of fabricated SIW structure 
using the adhesive material. During stacking process, a practical solution requires eight number of via holes in each fabricated SIW structure as the guided. By aligning each of the guided hole on both SIW structures, the cross-slot coupling position is correctly position. Then, a measurement is performed using Network Analyzer for design verification.

The comparison between simulated and measured results is shown in Figure 4. Almost promising results are observed within a frequency range studied of $9.2 \mathrm{GHz}$ to $11.2 \mathrm{GHz}$. Each measured resonant frequency of the dual-layer SIW structure indicated a shifting of $0.1 \mathrm{GHz} \sim 0.2 \mathrm{GHz}$ from the simulated results. The shifting of the measured resonant frequency is mainly caused by the slot alignment, which not correctly positioned during the stacking process. However, the measured bandwidth performance shows improvement from $1.8 \mathrm{GHz}(18.0 \%)$ to $1.9 \mathrm{GHz}(19.0 \%)$ compared to the simulated bandwidth.

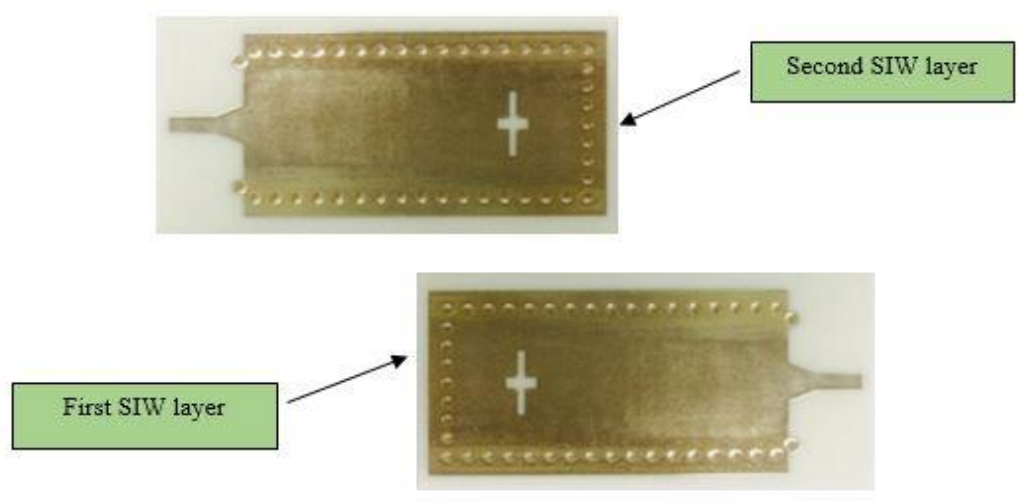

(a)

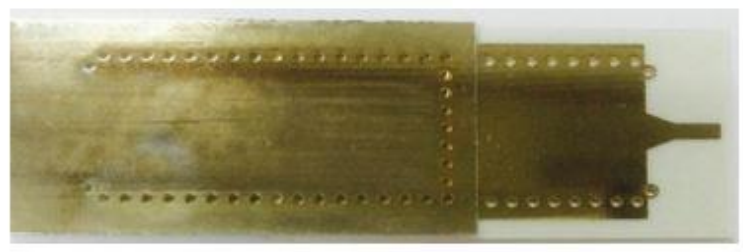

(b)

Figure 3. Fabricated of Dual-layer SIW Structure with Cross slot Coupling (a) Before and (b) After Manually Stacked.

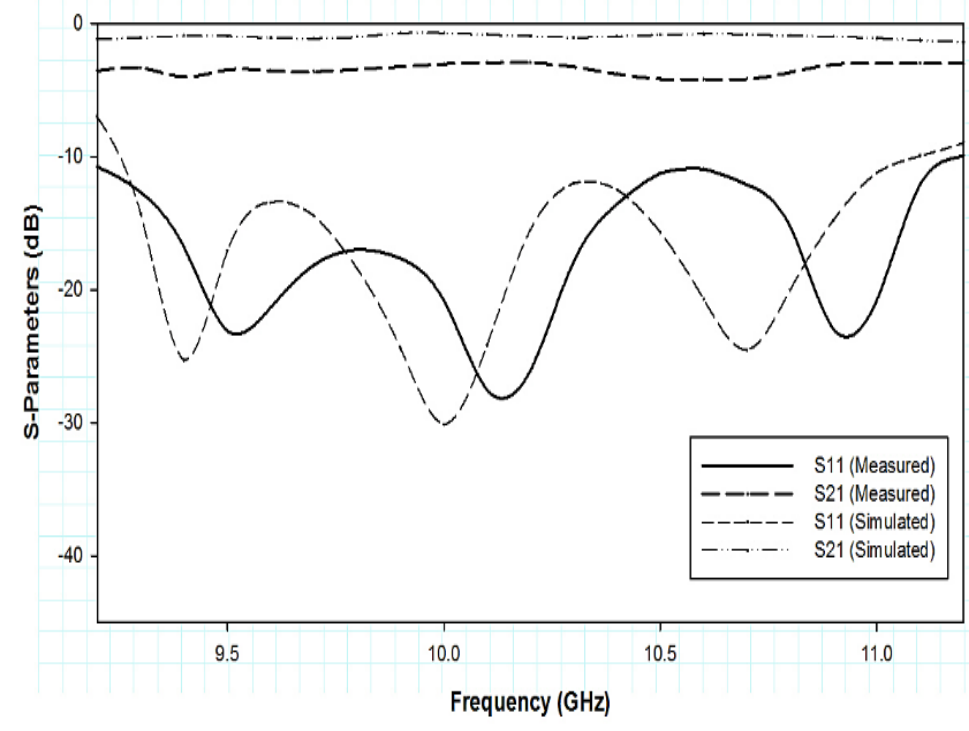

Figure 4. Simulated and Measured of Dual-layer SIW Structure with cross Slot Coupling. 
Then, a comparison between achieved results from the proposed dual-layer SIW structure with cross slot coupling design again a verified conventional multilayer transition design proposed by [8] is illustrated in Table 1. The proposed dual-layer SIW structure with cross slot coupling shows a good bandwidth compared to the conventional dual-layer SIW structure with rectangular slot coupling. At the operating frequency, 19.0 $\%$ of bandwidth is observed from the proposed dual-layer SIW structure with cross slot coupling, which indicated $9.0 \%$ bandwidth enhancement compared to the conventional dual-layer SIW structure with rectangular slot coupling design. Therefore, cross slot coupling design shows an advantage to allow more electromagnetic field in $T E_{10}$ mode of the dual-layer SIW structure to be coupled.

Table 1. Comparison between the Conventional Dual-layer SIW Structure with Rectangular Slot Coupling and the Proposed Dual-layer SIW Structure with Cross Slot Coupling.

\begin{tabular}{cccc}
\hline $\begin{array}{c}\text { Published } \\
\text { work }\end{array}$ & $\begin{array}{c}\text { Operating frequency } \\
(\mathrm{GHz})\end{array}$ & $\begin{array}{c}\text { Type of slot } \\
\text { coupling }\end{array}$ & $\begin{array}{c}\text { Bandwidth } \\
(\%)\end{array}$ \\
\hline$[8]$ & 10.0 & Rectangular & 10.0 \\
Proposed & 10.0 & Cross & 19.0 \\
\hline
\end{tabular}

\section{CONCLUSION}

A cross-slot coupling design in the proposed dual-layer SIW structure has been explored and demonstrated in this paper. The proposed design is realized by locating the cross-slot coupling design at the common metal surface of the dual-layer SIW structure as possibilities to enhance the bandwidth performance. The fabricated dual-layer SIW structure with optimized cross slot coupling design is fabricated, manually assembled, and measured for design verification. Almost promising results are observed within a frequency range studied of $9.2 \mathrm{GHz}$ to $11.2 \mathrm{GHz}$. A $19.0 \%$ bandwidth is detected from the fabricated duallayer SIW structure with cross slot coupling design, which showed $9.0 \%$ bandwidth improvement compared to the conventional dual-layer SIW structure with rectangular slot coupling. Therefore, the cross-slot coupling design shows possibility in order to enhance the bandwidth performance of the multilayer transition design.

\section{ACKNOWLEDGEMENTS}

This project is sponsored by the Ministry of Education Malaysia and Universiti Teknologi Malaysia under Vot 4J211, Vot 03G33, Vot 4J220, Vot 13H26 and Vot 11H59. The authors would like to thank the staff of the Wireless Communication Centre (WCC) of Universiti Teknologi Malaysia (UTM) for the technical support.

\section{REFERENCES}

[1] Abdel-wahab and S. Safavi-naeini, "Microstrip Patch Antennas ( MPAs ) Fed by Substrate Integrated Waveguide ( SIW )," IEEE Antennas Wireless Propagation Letters. vol. 10, pp. 1003-1005, October 2011.

[2] O. A. Nova, J. C. Bohórquez, N. M. Peña, G. E. Bridges, S. Member, L. Shafai, and C. Shafai, "Filter-Antenna Module Using Substrate Integrated Waveguide Cavities," IEEE Antennas and Wireless Propagation Letters. vol. 10, pp. 59-62, January 2011.

[3] M. Bozzi, F. Xu, D. Deslandes, and K. Wu, "Modeling and Design Considerations for Substrate Integrated Waveguide Circuits and Components," IEEE International Conference on Telecommunications in Modern Satellite, Cable and Broadcasting Services, pp. P-VII - P-XVI, September 2007.

[4] R. G, J. Zürcher, C. Peixeiro, and J. R. Mosig, "Broadband Ka-band rectangular waveguide to substrate integrated waveguide transition,” IEEE Electronic Letters, vol. 49, Issue 9, pp. 9-10, April 2013.

[5] C. L. Zhong, J. Xu, Z. Y. Zhi, and C. X. Jin, "Broadband Substrate Integrated Waveguide to Rectangular Waveguide Transition with fin-line," IEEE Electronic Letters, vol. 45, Issue 4, February 2009.

[6] Y. Li and K. Luk, "A Broadband V-Band Rectangular Waveguide to Substrate Integrated Waveguide Transition," IEEE Microwave and Wireless Components Letters, vol. 24, no. 9, pp. 590-592, September 2014.

[7] L. Li, X. Chen, R. Khazaka, and K. Wu, "A Transition from Substrate Integrated Waveguide (SIW) to Rectangular Waveguide," IEEE Microwave Conference, pp. 2605-2608, December 2009.

[8] M. N. Hafiz, M. Rafiee, and M. S. Aftanasar, "Design of a Rectangular Slot Coupling for Effective Transition Between Two Layers of SIW," 2015 IEEE International; RF and Microwave Conference, pp. 14-16, December 2015.

[9] D. Deslandes and K. Wu, "Accurate Modeling, Wave Mechanisms , and Design Considerations of a Substrate Integrated Waveguide," IEEE Trans. on Microwave Theory and Techniques, vol. 54, no. 6, pp. 2516-2526, June 2006.

[10] D.V. Navarro-Mendez, L.F. Carrera-Suarez, M. Baquero-Escudero, and V.M. Rodrigo-Penarrocha, "Two Layer Slot-Antenna Array in SIW Technology," IEEE Proceedings of 40th European Microwave Conforence, pp. 14921495, September 2010. 


\section{BIOGRAPHIES OF AUTHORS}
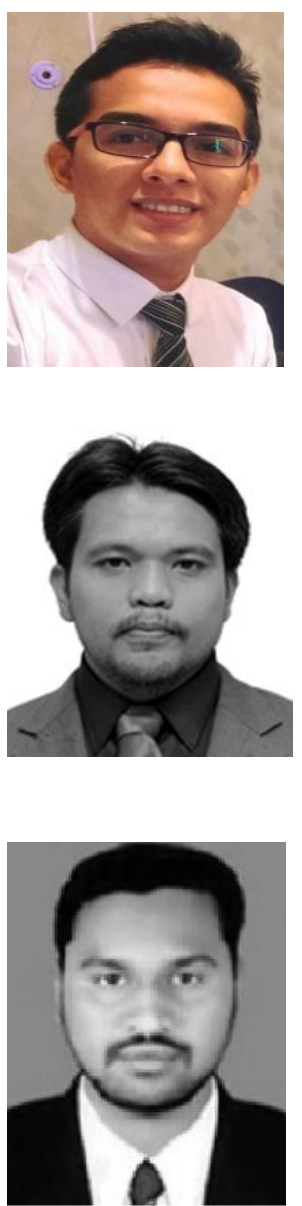

MUHAMAD HAFIZ was born in Kelantan, Malaysia, in 1991. He received the bachelor's degree in electronics and communication engineering and master's degree by research in year 2015 and 2017, respectively from University Science Malaysia, Malaysia. During his studies, he involves with antenna project especially Substrate Integrated Waveguide (SIW) antennas and Dielectric Resonator Antenna design.

MOHD HAIZAL JAMALUDDIN was born in Selangor, Malaysia, in 1981. He received the bachelor's and master's degrees in electrical engineering from Universiti Teknologi Malaysia, Malaysia, in 2003 and 2006, respectively, and the Ph.D. degree in signal processing and telecommunications from the Université de Rennes 1, France, in 2009, with a focus on microwave communication systems and specic antennas such as dielectric resonator and reflectarray and dielectric dome antennas. He joined the Department of Electronic Engineering, Faculty of Electrical Engineering, Universiti Teknologi Malaysia, as a Tutor in 2003. He is currently an Associate Professor with the Wireless Communication Centre, Faculty of Electrical Engineering, Universiti Teknologi Malaysia. His research interests include dielectric resonator antennas, printed microstrip antennas, MIMO antennas and DRA reflectarray antenns. He has published more than 80 papers in reputed indexed journals and conference proceedings.

RAGHURAMAN SELVARAJU was born in Gandarvakottai, Tamilnadu, India, in 1989. He received the bachelor's degree in electronics and communication engineering and master's degree in wireless communication systems in 2011 and 2014, respectively from Periyar Maniammai University, India. $\mathrm{He}$ is currently a Ph.D. Student and a Researcher with the Wireless Communication Centre, Faculty of Electrical Engineering, Universiti Teknologi Malaysia. His research interests include microstrip patch antennas, dielectric resonator antennas, MIMO antennas, beamforming array antennas, mutual coupling analysis, metamaterials, and split ring resonators. 